\title{
'No one is trash, no one is garbage, no one is cancelled': the cultural politics of trauma, recovery and rage in RuPaul's Drag Race
}

Debra Ferreday, Lancaster University d.ferreday@lancaster.ac.uk

\section{Introduction}

Widely seen as the embodiment of the histrionic, dramatic drag queen villainess and - more interestingly - dubbed 'the undisputed instigator of the season' (Dry 2018) as well as 'the whistleblower of the season' by fellow African-American contestant Monet X-change, Season 10 queen The Vixen subverted this familiar trauma narrative when, after refusing to tell her story in the accepted way, she 'stormed' offset - the show's interpretation of a rather dignified and low-key exit - leaving an absence which, I argue, constitutes a literal and figurative opening up around narratives of trauma, racism and recovery and their relationship to drag and celebrity culture. As a contestant on Season 10 of RuPaul Drag Race, The Vixen gained attention for her politically engaged persona: on the runway and off, her performance invoked the controversial cultural figure: that of the 'angry black woman' (Griffin 2012). Arriving on Drag Race with her own considerable following for both her activism and her show Black Girl Magic, she set out her stall as a fierce critic of intersectional oppression in queer communities (Hawbacker and Tucker 2016). Yet although her raw performances captured the attention of fans and judges, she was constantly embroiled in contrived conflict with white contestants, especially favourite and eventual winner Aquaria, attracting much censure after an episode of the backstage show Untucked where she was accused of 'making Aquaria cry'.

In Season 10 of Drag Race, the 'problem' of Vixen's excessive black rage became a central narrative arc, coming to a head in the show's reunion episode when she walked off set. This premature exit was greeted by RuPaul with an extraordinary attack that recalled Banks' infamous, and meme-worthy, 'we were all rooting for you' speech to a black contestant in Season 4 of ANTM, an intertextual reference that was not lost on the show's media savvy fandom. Dispensing with the stately, proper 'mama Ru' persona that underpins RuPaul's celebrity image (Dry 2018), she berated the remaining contestants:

But look at me, look at me, goddamnit! I come from the same goddamn place she comes from! And here I am! You see me walkin' out? No, I'm not walking out. I fucking learned how to act around people and how to deal with shit. I'm not fucking walking out and saying, 'Fuck all y'all!' That's disrespectful. To each of you [the other contestants]

\footnotetext{
${ }^{1}$ RuPaul's Drag Race: Untucked! Season 10, episode 3, Diva Worship. VH1: 14 March.
} 
It was left to a weeping Asia to challenge this narrative by invoking the values of queer pride for which Drag Race purportedly stands: but RuPaul rejected this, concluding that the Vixen was 'beyond help'.

In storming offset, The Vixen enters into the long line of feminine celebrities, and wannabe celebrities, positioned as 'beyond help': her 'disrespectful' behaviour is implicitly tied to notions of madness and of black rage that are understood as outside the show's understanding of appropriate black celebrity. Predictably, the show attempts to manage this through the discourse of the celebrity feud - pitting The Vixen firstly against Aquaria's blonde white 'good girl', and ultimately against Ru's figuring of a black drag femininity that is represented as desirable through its flexibility in both embodying tropes of ideal whiteness and in its ability to cover over black rage. What is dynamic and exciting about the Vixen, though, is that she refuses to be silenced: that her exit from the show, and triumphant return on social media, opens up the possibility for a new form of drag celebrity that incorporates the very tensions within queerness, femininity and blackness that are suppressed in RuPaul's version of black drag celebrity. As such, she operates as a queer celebrity who also queers the fantasies of postraciality and post-madness that are always at stake in celebrity media. Following from her alleged 'flounce', The Vixen's return on social media created an important space for this critique of Drag Race's recovery politics. As she famously declared: 'No one is garbage. No one is trash. No one is cancelled. Everyone can be wrong and learn from it and grow. People are not disposable'. In both playing with and critiquing cultural tropes of the celebrity feud, the Vixen is thus able to mobilise her own lived experience of trauma and racialisation on her own terms, building her already considerable celebrity platform to ask trenchant questions about the compromises at stake in Drag Race's translation of queer performance for a mainstream audience.

On one level, this is standard Drag Race drama, comfortingly familiar in its repetition of favoured practices: throwing shade, reading, 'realness' and of the bad girl/good girl tropes that have always circulated in celebrity culture. But Aquaria's white tears also need to be read in the context of wider debates about who gets to display emotions, and whose emotions are taken seriously. As The Vixen herself astutely commented: 'you have created a narrative of I am an angry black woman who has scared off the little white girl'. This skirmish, I argue, dramatizes wider debates about gender, racialisation, and the boundaries of appropriate celebrity, as well as invoking questions about whose drag counts as 'authentic'. As feminist scholars Elizabeth Cole and Alyssa Zucker argue, 'the concept of femininity has long been fraught for Black American women in particular' since 'they have historically been treated as though they exist outside of its boundaries as they faced economic exploitation, virulent stereotyping, and lack of legal protection by virtue of their race' 2007: 1). In the context of a culture that already positions Black women's bodies as the constitutive outside of the feminine ideal, Black queens are already disadvantaged. After all, RuPaul himself is presented as a figure of aspiration for other queens of colour, who are told they must work harder than white 
contestants to produce an ideal femininity that is not only a parody of femininity, but of black parodies of white beauty ideals. Like his counterpart Tyra Banks on America's Next Top Model - of which Drag Race started life as a parody and has become an increasingly unironic facsimile - RuPaul has often treated Black queens who fail to achieve this rigid standard of racially ambiguous beauty to a disproportionate dose of tough love. Presented as a star whose evolution from genderqueer club queen to global celebrity to international star is intimately bound up with her adoption of Jane Fonda's iconic Barbarella look - and hence with white, retro ideals of feminine glamour - RuPaul defines the limits of drag celebrity, I argue, in ways that often work to exclude and marginalise black queens who exceed those limits. The spat between RuPaul and The Vixen is therefore not simply part of the familiar battle between host and performer, as seen on ANTM, but a struggle over ownership of Black queer celebrity: and especially over who gets to speak about queer and racialised trauma, and how.

Recent scholarship in media studies has drawn attention to the centrality of personal trauma narratives in popular television and the role of reality stars in enabling and exploiting public displays of trauma (Biressi and Nunn 2005, Ouellette and Hay 2008). As Anita Biressi and Heather Nunn have argued, the consumption of personal trauma narratives is one of the pleasures of reality television (2005: 5); 'the exposure and, more particularly, self-exposure of psychological and bodily trauma' has become 'the central feature of our post-documentary culture' (2005: 7). TV formats produce narratives of 'personal pain, injury and loss'; the use of techniques of 'confession, video diary, interview, observational techniques' indicates 'the embedding of the revelation of trauma and psychological damage in post-documentary formats and its relationship to the broader psycho-social realm of an established therapeutic culture' (2005: 8).

In his work on trauma, Roger Luckhurst examines how Oprah Winfrey's celebrity centres on a sense of intimacy with the mass audience. While the wealth, fame and cultural influence of the celebrity host mark her as exceptional, he argues, her trajectory embodies the neoliberal therapeutic narrative that 'psychological disadvantage can be superseded by the exercise of the will' (2008: 133). For Eva Illouz (2003), the trauma narratives at stake in Winfrey's celebrity performance 'embody modern tragic narratives of the suffering self'; recovery culture engenders a 'deep narrative of the self through suffering', 'a powerful identity narrative that provides a "centre" to the self by stitching together past and present' (cited in Luckhurst 2008: 134).

RuPaul engages in just such 'trials of authenticity' yet also paradoxically satirises them. Drag has long been regarded as revealing the instabilities at stake in normative expressions of femininity. Yet ironically, as a celebrity matriarch of colour in the Tyra or Oprah mould and who aspires to build an equally dominant brand identity, 'mama Ru' plays a policing role, providing closure for contestants who demonstrate the ability to appropriately perform and commodify their trauma, while expelling 
those who fail to do so - not matter how productive that failure might be. How, then. Might these theoretical voices be brought into dialogue with multi-media responses to the 'Vixen controversy', and the way this incident as a skirmish that speaks to wider debates about mental illness and fantasies of postraciality?

In this paper, I examine how The Vixen's fracturing of the preferred Drag Race story arc resonates with queer scholarship, which has been attentive to the imperative to tell positive stories, and the way this silences melancholic, 'negative' voices. Heather Love writes of a tension in queer studies between the need to speak of 'damage', and a 'related and contrary desire to affirm queer existence' (2007: 2). Seen in this context, the Vixen's 'flounce' and return reveal the tensions at stake in queer media that operate at the intersection of these two conflicting and entangled imperatives. Further, Drag Race needs to be situated within a wider history in which madness and black rage have paradoxically been positioned as outside culture through regimes of hyper-visibility as well as in relation to current neoliberal narratives of stigma and 'recovery' (Costa 2014). Drawing on critical mental health scholarship, I argue that a mad reading of The Vixen's arc within the series and her refusal to complete that arc - and by extension of the show's treatment of other 'difficult' queens of colour - enables new understandings of the ways in which mad subjectivities intersect with racialised and gendered oppression, and the way these are struggled over in celebrity culture. In this sense, The Vixen's exit from Drag Race can be read as the culmination of a mad, queer and antiracist critique of the show's recovery politics, both in itself and in the fan and critical responses it engenders, and that opens up new ways of living with the difficult, ugly emotions that popular recovery narratives demand we relegate to the past.

\section{Screening Trauma}

During its 10-year run, Drag Race has attracted hyperbolic praise for its support of the marginalised and outcast within society and in the drag community, preaching a gospel of self-love and self-care through themantra: 'if you can't love yourself, how in the hell are you gonna love somebody else?', a phrase always greeted with mandatory cries of 'amen' and joyful dancing. Historically, it has mobilised individual stories about homophobia, family violence, racism and femmephobia, encouraging participants to speak out about these experiences in order to overcome them. The show has been described as 'much like drag itself ... reality TV's limit case, maximizing the entertainment value of its contestants' personal histories' whose 'added layers of performance (on camera and on stage) and the salient LGBT issues make these moments ring all the more true, in a refreshingly direct way' (Betancourt 2016). Contestants have spoken about mental illness, HIV, gender transition, racism, Islamophobia and homophobic violence, usually in a supportive environment that celebrates queer survival above all else. This celebration of the weird, marginal and outcast is central to fan accounts of Drag Race, as exemplified in Season 4 when the show's audience were invited to help 
choose the winner, overwhelmingly voting for Gothic drag weirdo Sharon Needles. As cultural critic Domenick Scudera argues:

'[in voting for Sharon Needles] People were actively engaged in supporting the weirdo, the victim, the vulnerable one. Hopefully, this outpouring of love managed to find its way to the kids out there who are being bullied right now. The message to these kids is loud and clear: ... RuPaul loves you; the nation loves you' (Scudera 2016)

Drag Race's runway, workroom and wider community are hence presented as a holding space, a site of queer kinship that fulfils contestants' historically unmet need for love and acceptance. This is reinforced by RuPaul's role as symbolic mother whose star persona invokes a kind of eternal, idealised queer femininity rooted in ballroom, with its tradition of drag mothers, but also in tropes of ageing female celebrity. In mentoring exchanges, Ru appears as a therapist figure, dispensing often highly simplistic soundbites whose often victim-blaming content is at odds with their performative warmth and kindness, as In Season 7 when she tells Katya - who has struggled with substance abuse issues, anxiety and depression - 'you seem to be addicted to anxiety' ${ }^{2}$. The creation of drag celebrity, then, is deeply entangled with a confessional imperative; in order to achieve (albeit reduced) star status, contestants must consent to be broken down and rebuilt in RuPaul's own image.

This means Drag Race demands the constant production of personal trauma narratives in order for its narrative arcs to function. In Season 2, fan favourite Pandora Boxx movingly recounted how her experience of homophobia drove her to attempt suicide. Most notoriously, Season 5 queen Roxxxy Andrews recounts how her mother abandoned herself and her sister at a bus stop when she was three: as she collapses into tears, she is told, 'we love you, and you are so welcome here. You know we as gay people, we get to choose our family, we get to choose who we're around. We are a family, we are family here. I love you. I love you ${ }^{3}$ ' as judges Michelle Visage and Ru are shown delicately dabbing at tear-filled eyes, their performance of ladylike grief in stark contrast to Roxxxy's uncontrolled uglycrying. To soaring, emotional music she is told, 'what you did on this runway is the passion I am looking for', the production of personal pain equated with winning in an almost parodic performance of neoliberal accounts of recovery. This is the 'money shot of emotional collapse' described by Luckhurst; the attainment of celebrity turns on this moment of confession 'expertly steered by [the host's] empathic identification with virtually any manner of suffering' (2008: 133). The episode ends - of course - with a group hug, signalling the re-incorporation of the traumatised subject back into the group 'family'. This is an ambiguous moment, inviting empathy but at the same time reminding us that in reality TV, 'confession, exhibitionism and emotional revelation [are] the conspicuous watermarks of authenticity and ethical commitment to audiences' (Biressi and Nunn 2005: 7).

\footnotetext{
${ }^{2}$ RuPaul's Drag Race, 2015 Season 7, episode 7, Snatch Game. Logo TV, 13 April.

${ }^{3}$ RuPaul's Drag Race, 2013 Season 5, episode 7, RuPaul Roast. Logo TV, 11 March.
} 
To understand how The Vixen's fracturing of this happy family narrative opens up the potential for a more radical discussion of queer trauma, it is productive to turn to recent scholarship in Mad Studies. Lucy Costa defines this fluid an open field as 'an area of education, scholarship, and analysis about the experiences, history, culture, political organising, narratives, writings and most importantly, the PEOPLE who identify as: Mad' psychiatric survivors; consumers; service users; mentally ill; patients, neuro-diverse; inmates; disabled -to name a few of the "identity labels" our community may choose to use' (Costa 2014). As such it is not simply a product of academic research but a wider 'project of inquiry, knowledge production and political action' (LeFrancois et al 2013: 13) which draws on histories of survivor activism and on methods and conceptual frameworks from women's studies, queer studies and critical race theory, among others, mad studies suggests a radical critique of the 'recovery model' of mental illness at stake in contemporary anti-stigma campaigns and in celebrity media.

To this end, mad scholars have been critical of the voyeuristic nature of reality TV and celebrity culture, with its relentless demand for more horror stories, more coercively performed 'authenticity'. Seen through this lens, Drag Race feels uncomfortably close to what Costa et al term 'survivor porn', in which 'some people reveal their most intimate personal details, [while] others achieve relief through passive watching, while still others profit from the collaboration of those on the front lines in compromised positions' (2012: 86). Drag Race's recovery stories, then, are part of a more general cultural shift in which 'telling stories' about mental health and trauma becomes a way of reinforcing rather than challenging neoliberal models of recovery, labour and social governance. 'Telling your story', usually with the nebulous aim of 'reducing stigma', becomes a way of individualising experiences of mental distress, making some forms of social inequality hyper-visible and concealing others. Ideas about recovery and self-expression are central to the show's ethos, which produce drag as a technology of recovery: a means of standing up, making up, walking tall and rising above trauma, embodying the notion that 'it gets better' (Scudera 2016). The progression from local celebrity to Hall of Famer is depicted as individual journey of self-discovery that leads away from pain: as Alyssa Edwards puts it, 'don't get bitter, just get better' ${ }^{4}$. Favoured stories 'feature the uplifting message that with a little hard work and perseverance, you too can be cured' (Costa et al 2012: 89). And yet the familiar tropes of reality TV - zooming in on crying faces, the use of sentimental music to heighten particularly emotive scenes, the deliberate provocation of conflict in order to profit from distress - sit in uneasy tension with this optimistic narrative. To continue to be traumatised under such scrutiny marks contestants as beyond help: that is, as mad. As Simon Cross notes, 'mad' subjects are represented as the constitutive outside of culture (204: 199). In this instance, they threaten both the

\footnotetext{
${ }^{4}$ Edwards, Alyssa (2013), Drag Official, Tumblr, https://tinyurl.com/yx9de7cz
} 
happy queer postracial family the show invokes, and the boundaries of appropriate drag celebrity itself, echoing Lisa Blackman and Valerie Walkerdine's analysis of the way madness threatens the limits of the unitary subject: 'having lost the ability to distinguish self and other' such that the mad subject is 'viewed as a danger to both himself and the public at large' (2001: 126).

As Cross reminds us, representation is central to discourses of madness: the mad subject is overwhelmingly represented through the idea of "visible differences of appearance and behaviour that demarcate a symbolic boundary between "us" and "them" (Cross 2004: 199). Celebrity culture has historically been concerned with the delineation of this boundary: it is often through celebrity figures that anxieties around trauma and madness are negotiated and struggled over. As such, it operates within a wider history in which mad bodies have paradoxically been positioned as outside culture through regimes of hyper-visibility (Gilman 1976, Showalter 1987, Cross 2004). In particular, current antistigma discourse has been critiqued for its oppositional framing of the redeemable subject suffering distress versus the irredeemably mad, an opposition which both obscures and reproduces social inequality: or as Brigit McWade argues, 'representing mental health as everyone's business belies the significant inequalities inherent in our current system' (2018: 158). The overdetermination of stigmatised bodies in celebrity culture matters, since it works to silence questions of actual social inequality 'with the promise that once we understand the facts of mental illness, stigma will be eradicated' (ibid).

This resonates with fan responses to Drag Race, in which 'somewhere along the line people accepted the values of Drag Race as universal, moral fact; that the way to overcome is to pull yourself up by your bootstraps', as one critic put it (Flores 2017). Although the show overtly takes it responsibility to LGBTQ+ audiences seriously in a context where queer subjects are disproportionately likely to suffer from mental distress (McDermott and Roen 2016), it is less willing to reflect on its own complicity with the conditions that cause or intensify distress. Thorgy Thor, who appeared in Season 8 and has depression and anxiety, has spoken of how the emotional labour involved in drag celebrity contributes to the severity and frequency of symptoms, noting that drag queens 'never sleep, we perform, people expect us in the subway to 'turn on the fun' when we don't feel like it or we're just shopping at the grocery store' (Nichols 2018). Sharon Needles tells of the emotional and physical toll taken by 'being in drag from 7.30 in the morning until 11.30 at night', at the mercy of continual attempts by producers to stoke conflict (Fossum 2014). These experiences suggest something messier, less linear, than the stories of recovery we see onscreen. Yet 'winning' is always figured as a process of becoming-sane that refuses the more creative - and also more difficult - affordances at stake in mad subjectivity, and in drag as an art form. In representing mental distress as something to be discarded on the road to fame, Drag Race risks closing down radical possibilities for queer solidarity, repeating the tired and oppressive celebrity tropes that position the 'hot mess' outside the boundaries of appropriate celebrity. At the same time, its very mainstream visibility, together with the intersection between different 
media spaces, platforms on which the show depends, mean that this closure is never complete. In order to understand how this struggle plays out in practice, I want to examine how narratives of queer and Black rage play out across their very different celebrity platforms.

\section{Refusing black rage: RuPaul's Cruel Optimism}

The Vixen's constant destruction-testing of the narratives of queer and postracial optimism at stake in Drag Race's ethos, her pushing at the boundaries of acceptable behaviour for a celebrity queen, can be seen as a dramatization of Lauren Berlant's theory of cruel optimism, defined as 'how we are bound to desired futures that prevent us from flourishing in the present' (2011) in 'something you desire is actually an obstacle to your flourishing' (2011: ix) . Optimism is doubly cruel, she writes, when 'the very pleasures of being inside a relation have become sustaining regardless of the content of the relation, such that a person or a world finds itself bound to a situation of profound threat that is, at the same time, profoundly confirming', a formula which precisely speaks to the attachment to fame embodied in Drag Race (2011: 2). This speaks to the drama of the reality TV celebrity who must constantly relive trauma: because this reliving is presented helpful to others, both in providing a point of identification for fans and in challenging stigma, its potential to re-traumatise is never acknowledged. Paradoxically, contestants are made to relive trauma over and over again, a relation which looks less like therapy and more like the dynamic of trauma itself, which precisely binds us to abusive pasts through emotionally charged repetition. Contestants are trapped in these stories even as they are urged to move forward into a future in which freedom is envisaged as one where individual self-love is reinforced and mirrored by the love of the audience. After all, 'if you can't love yourself, how in the hell are you gonna love anyone else' - a feelgood phrase which invalidates the actual capacity of traumatised subjects to love alongside living with their wounds. If we focus on the show's use of trauma narratives, we see in action Berlant's argument that it is the very pleasure and investment in therapeutic cultures by participants and fans alike that prevent actual connection through the articulation of more painful, difficult, contingent relations to trauma than the show's format allows. Focussing on drag - and the way that flounces, absences, critiques and breakdowns are enfolded into and extend drag performance - it is possible to find more creative approaches to survival which resonate with performers and audience alike. In fact drag itself - where the dazzling and seamless illusion we see on the runway is achieved only through intense labour, discipline, and creativity - represents a more progressive model of survival, and of self-care, than the show's actual discussions of mental health.

Further, Drag Race shows us that optimism perhaps is most cruel when we invest it in celebrities and forms of popular entertainment that appear to provide a place of safety, because they so often disappoint us. This is starkly clear when we examine the show's racial politics, which, far from delivering on this promise of queer optimism, suggest a more ambivalent relationship to structural 
violence. If, as I argue, drag can be read as a complex technology of survival, Drag Race's performances of racial identity doubly fail to achieve this potential. In producing drag as a means of soothing social anxiety through containment and closure, and especially in producing drag celebrity as a pyramid scheme in which trauma exists only in order to showcase one's ability to overcome it, the show forecloses possibilities for less hierarchical queer solidarity. This is never more visible when it gestures to a postracial future that operates by ascribing 'sensitivities' about racism to a past which, paradoxically, constantly erupts in the present.

This is evident in Season 9, where one of the story arcs between episodes was that of Nina Bo'Nina Brown, whose uncompromisingly confrontational drag and struggles with depression led to a narrative of white queens' resentment at having to "deal with Nina". Brown was constantly criticised for her low self esteem: as one white contestant put it, "we can't stop cheering for her [sic] when she isn't even willing to cheer for herself." Another contestant, in full command of Drag Race's lexicon of neoliberal recovery discourse, insisted that in terms of depression 'you are fully in control of what sort of day you're going to have'. Nina's storyline, with its tragic narrative of failed potential, reveals a tension in which the show both invokes therapeutic discourse, and yet is unable to reflect on its own complicity in reproducing ableist and racist narratives. As one critic summarises,

At the end of the day, Nina isn't given the same autonomy that white queens are given ... No one wants to embrace the complexity, the good and badness of being a queer person on a violent, hateful planet. They just remind us that it's not "RuPaul's Therapy Race“ (Flores 2017)

The narrative of queer family as welcoming and supportive home, and of transcendence through fame, fractures at the moment when a queen is unable to 'recover' from depression at a pace compatible with cliché character arcs. Persistent depression breaches the established boundaries of confessional storytelling, stubbornly refusing conventional resolution; it can be messy, unattractive, and nonlinear: worse, the cruel optimism at stake in the notion that 'it gets better ${ }^{5}$ can be traumatising in itself for subjects whose attempts to manage and overcome their distress are inevitably read as failure, a notion that can be actively dangerous when internalised. That Nina's drag continued to push creative boundaries in spite of her obvious despair and alienation failed to save her: instead - remarkably in a format that celebrates the creativity, artifice and adaptability of oppressed subjects - Nina's 'madness' negates and cancels her spectacular performances on the runway. Not only is continuing to be depressed a choice; winning contestants are defined as such precisely by their ability to internalise the notion of all emotion as personal choice, and to incorporate this into their drag. This is nowhere more visible than in the show's approach to racial pastiche.

\footnotetext{
${ }^{5}$ See Puar (2012) for a more detailed critique of the ways in which Dan Savage's 'It Gets Better' project reproduces neoliberal values, and how this might be productively challenged.
} 
Throughout Drag Race's run, black and minority ethnic contestants have been urged to resolve racial trauma by engaging in self-conscious parody of racialised tropes, often resulting in highly offensive performances based on racist, classist and orientalist stereotypes (Han 2015, Garvin 2019). As with RuPaul's own persona - not so much a parody of white femininity as of black female stars' adaptability in incorporating white beauty ideals - the requirement to 'laugh off' the pain of racist stereotypes is inextricably stitched in to Drag Race's notion of ideal drag celebrity. This double requirement - that black queens both embody white beauty ideals, while also demonstrating the ability to perform racist tropes - is particularly difficult for the Vixen, whose own celebrity involves recognising racial politics and celebrating black identity. In a parody of cis black feminine celebrity, black queens must avoid appearing too political, too 'messy', and above all too angry; Black bodies are hence repeatedly prioritise the need to manage the fears and anxieties of the white audience over any responsibility they may feel to fans of colour. Queens of colour have been praised for stereotypical racialised performances, such as Stacey Lane Matthews' embodiment of the fried chicken eating 'Welfare Queen' image, a figuration of grotesque, excessive femininity that is deeply gendered, racialised and classed. Through this labour, racism is 'made safe' for performer and audience alike, suggesting that drag celebrity must manage and conceal its distress to connect with an audience that needs to be comforted and protected from the painful reality of white supremacy.

This became starkly clear when Asia O'Hara told Twitter about a childhood incident when her neighbours attempted to set her on fire for being gay; explaining that trolls had recently threatened to set her on fire again, this time because she is Black, an experience that re-traumatised her (Damshenas 2018). Far from being left behind, Asia's trauma re-surfaces because it is intrinsically linked to the structures and politics of the present, as a result of her new visibility as a celebrity of colour. In mad spaces, much attention has been paid to the cult of toxic positivity, and the ways in which it operates to invalidate negative feeling, discourage structural critique, silence real experiences of distress. It is impossible not to hear its echo in RuPaul's own remarks about what he sees as the unattractive and unsaleable nature of black rage and the extent to which Drag Race's appeal lies in its avoidance of those aspects of the African American experience that white audiences find least palatable:

People have always been threatened by me as an African-American man, because of the inherent black rage that all black people have in our culture, the underlying black rage because of what happened to us in this country. It's always there ... one of the ways that I've been able to dilute that perception is to dress as a character that says, 'Look I'm fun, I can have a sense of humour about life because I'm in drag. ... So then people are like, 'Oh, OK, so we can laugh together, we don't have to address the black rage.' (Aitkenhead 2018)

Not speaking about black rage thus becomes a way of maintaining star status and securing the attention of a white supremacist audience: the creation of positive connection turns on the 
marginalisation of subjects who are not able to leave their experience of racial inequality at the door. In this light, the show's constant reproduction of racist tropes begins to look less like an attempt to rid these tropes of their power to hurt, and more like the visible symptom of rage turned inward. In other words, the performance of appropriate celebrity is intrinsically tied up with the labour of internalising and reproducing toxic positivity. Fame itself, then, is a kind of labour of toxic positivity that is most visible in representations of the damaged celebrity.

Again, this echoes mad critiques of the white supremacist values inherent in recovery discourse. As Dom Chatterjee argues, in order for the recovery journey to make sense we are supposed to accept that trauma is in the past, even as it is constantly dragged out for public consumption. But when trauma is tied to systemic oppression, leaving it in the past is both impractical and politically undesirable: 'Given that safe spaces are an ideal, not a reality for most of us, these kinds of statements are invalidating. If feeling safe is a required condition for healing, that makes any kind of recovery inaccessible to those of us enduring chronic trauma from the world around us'. He concludes, "we are expected to get well, [but] nobody asks if the picture of wellness that's supposed to be the end goal is even good for us' (2017). The lack of safe spaces is made even more stark in celebrity culture, where intimacy and accessibility are key.

I should say, here, that all this is emphatically not to say that there is no hope, that healing is impossible; nor am I denying the importance of these queer life stories being told in such a popular format, or of their power to move. It would be a detached critic who managed not to weep along with Michelle, Ru and Alyssa during such moments of high drama. Nor am I suggesting that testimonies of abandonment, trauma and loss are necessarily deprived of their power when presented in a highly dramatic, emotionally charged way. Whatever our justifiable scepticism towards the 'it gets better' narrative, there is something deeply distasteful about criticism which seeks to police the way in which survivors get to speak about and profit from their stories. As the show's fan spaces demonstrate, contestants' testimonies can be a lifeline for viewers experiencing similar pain. Many have written of the show's importance as part of an assemblage of self-care: those of us who live with depression, for instance, might recognise ourselves in Melanie McFarland's moving account of ' $\mathrm{Ru}$... calling people - calling me - to lip-sync for my life. To wake the hell up and be gorgeous again' when 'the very concept of gorgeous was altogether forgotten, a memory as garbled and scratchy as an old club track' (2016). This deeply camp version of what it means to live with mental distress - the idea that the show must go on, hiding broken hearts behind sequins and greasepaint - has always been entangled with queer and femme celebrity. As a way of coping with mental distress it has its advantages over the dour self-discipline, the earnest mindfulness, the white bourgeois back-to-nature, anti-culture tropes that the contemporary recovery ethos all too often involves. Through affective identification with drag celebrities, it seems, a different way of living with trauma might be possible. Far from mere reality TV exploitation, Drag Race's constant exhortation to love oneself (and through doing so, to become 
more open to loving others) is grounded in queer practice: as Manuel Betancourt (2016) writes, the 'rhetoric of self-love as a form of self-care has always been essential in the world of drag' ${ }^{6}$.

Yet we need to remember that this identification, this weeping along, takes place in a world where Aquaria's white tears are culturally valued, where they enhance her celebrity capital in a way that The Vixen's anger, or Nina's continuing pessimism and negativity, are not: where we are encouraged to identify with Roxxxy's pain, but to disavow The Vixen's rage. RuPaul's ultimate inability to understand, to hold space for queer black rage, is disappointing precisely because of drag's origins in spaces of queer and racialised trauma, as a way of living-as marginal subject. In his parody of Oprah and Tyra-like figures, RuPaul proposes a new way of doing celebrity: one which recognises the freaky, the marginal, the different. Yet his failure to embrace The Vixen's drag, which takes up the figure of the angry black woman in a genuinely exciting way that exceeds the boundaries of accepted Drag Race celebrity, producing a moment of productive mad and queer failure, reveals this as cruel optimism. In the reunion episode, RuPaul's angry monologue turned on the Vixen's perceived negativity, her frustration at being silenced, and ultimately her use of silence and absence as the only remaining forms of protest available to her. In choosing the established tropes of celebrity culture over a more open-ended and honest resolution, the show misses an important opportunity to speak differently about queer trauma - whatever that might mean.

In suggesting that trauma narratives are constructed and artificial, finally, I am not suggesting that they are necessarily inauthentic or that there is some 'truly authentic' form of survival narrative that reality TV formats conceal; nor am I proposing that the Vixen's performance is 'more authentic', since to do so would be to reproduce problematic discourses that have always constructed black bodies as Other. But in acknowledging the power of self-care discourse, it becomes all the more critical to pay attention to what it excludes: to what happens when perceived 'madness' threatens to exceed the boundaries of socially permitted trauma narratives - when drag itself becomes a performance of black distress, black rage: when it questions the value of contrived redemption arcs in a world that literally wants to set you on fire. Refusing the melancholic reproduction of racial stereotypes the show typically demands, The Vixen's performance of excessive black femininity speaks both to the reality of oppressive social structures and to the intimate and personal experience of distress that living within such structures entails. Importantly, in opening up this space, she enables a refiguring not just of the way we think about queer trauma, but of the way trauma is implicitly represented, contained and struggled over in celebrity culture as a whole.

\footnotetext{
${ }^{6}$ More recent reality TV productions have foregrounded self-love to an even greater extent than Drag Race, to equally problematic yet moving effect: see for example the rebooted Queer Eye, whose 'fab five' embody this version of queer celebrity as self-love guru.
} 


\section{Conclusion: being irredeemable}

In refusing containment, Vixen resists the desire to consolidate a sense of one's self in a culture seemingly devoid of meaning' that reality TV demands (Biressi and Nunn 2005: 100). If therapeutic discourses provide a language through which to make sense of subjective experience in a world where 'power structures and decision-making processes appear to alienate and exclude the individual' (Biressi and Nunn 2005: 104), in becoming irredeemable, she opens up a space to affirm the very queer trauma and black rage which Drag Race attempts to resolve. In the exhortation to 'just get better', the popular image of the mad 'as aggressive, out of control, and unable to normalise their behaviour' (Cross 2004: 205) is not disrupted, but is instead displaced on to participants whowhether for reasons of ongoing distress, or a political commitment to refuse incorporation - are unable or unwilling to 'normalise their behaviour'. In becoming absent, she reveals the limitations of popular trauma narrative: to speak of the mental distress occasioned by trauma thus requires a commitment to recovery which is precisely a disavowal of mad identity. Hence, the mad subject cannot speak, since the very conditions of speaking entail a commitment to becoming not-mad. To refuse such a commitment is to be positioned as both difficult and dangerous. The conversations she engenders, through her willingness to embody the 'trash, garbage and cancelled', demonstrate Judith Butler's argument that it is wrong to conceive of individual bodies as completely distinct from one another, that 'we cannot imagine the political meaning of human body without understanding those relations in which it lives and thrives': that 'the body, despite its clear boundaries, or perhaps precisely by virtue of those very boundaries, is defined by relationality' (2014). 'Making connections' here becomes not simply a matter of incorporating culturally scripted conversations into our everyday practice, but of producing new social frameworks that allow subjects to speak from a space of trauma, and to question the very conditions of labour and spectatorship that structure those conversations. They make visible the ways in which institutions, nations and communities secure complicity with normalised regimes of violence through techniques of silencing and shaming, and they do this all the more powerfully since they provide spaces for acknowledging histories of shame without immediately demanding an individual commitment to overcoming. To quote Sara Ahmed, emotions 'create the very effect of the surfaces or boundaries of bodies and worlds ... emotionality involves movements or associations whereby "feelings" take us across different levels of signification, not all of which can be admitted in the present'; they are hence 'bound up with the "absent presence" of historicity' (2004: 117 - 119). This has implications for our understanding of some subjects, feelings or behaviours as disordered; our dominant framing of madness precisely turns on the production of some emotions as both excessive (causing distress to the subject) and insufficiently internalised (causing distress to others). Madness hence threatens the boundary between self and other, carrying a danger of social disruption 
that demands containment. This threat is both denied and implicitly acknowledged in the currently fashionable exhortation to 'speak out' about mental distress.

For Love, there is power in those things that cannot be redeemed, or whose redemption cannot be accomplished through worn-out cultural scripts available to us. As she argues, 'Texts or figures that refuse to be redeemed disrupt not only the progress narrative of queer history but also our sense of queer identity in the present. We find ourselves deeply unsettled by our identifications with these figures: the history of queer damage retains its capacity to do harm in the present (2007: 8 - 9)'. Above all, The Vixen poses the question: what if it doesn't get better - or gets better only in contingent and messy ways? And how might surviving precisely as a body-in-distress in itself constitute a radical act? This not only challenges dominant ways of thinking about mental health and trauma, but allows us to rethink the ways in which media exploits the notion of the celebrity "hot mess' through cycles of repression and excess.

In this context, the 'angry black woman' as multimedia drag persona becomes a focus of productive failure: failure to produce idealised white femininity, to appropriately manage emotion, and to deny and internalise black rage. Seen in this light, The Vixen does not 'fail' at drag celebrity on the show's terms, but rather expands our sense of what drag celebrity can be and do. This resonates with Rachel Alicia Griffin's powerful reclaiming of the 'angry black woman' as a figure who can 'do the very things that Black women are discursively disciplined not to do. I will rant without a hint of regret ... with my head held high believing that I am worth standing up for in a world that crudely tells me otherwise' (2012: 138). In taking herself literally out of the limited frame that Drag Race allows black queens, Vixen is able to take control of her narrative through a critical moment of fragmentation in the cruelly optimistic fantasy of recovery at stake in Drag Race's version of drag celebrity. In a context where celebrity culture increasingly functions as a way of thinking through the ways in which historical trauma survives in the present, her dramatic exit and return constitute a powerful refusal of celebrity damage narratives that insist on dominant notions of recovery. In refusing erasure, she shows us a creative and fiercely celebratory way of affirming damage. If we resist the idea that particular identities, bodies, emotional orientations are in need of correction and containment, what newer, more radical forms of connection might be possible? Further, how might this require us, as audiences and critics, to examine our complicity with the violence inherent in such narratives of correction, and the disproportionate demands such narratives make on contestants with marginalised identities? As critic Matthew Rodriguez (2019) asks: 'what, then, does it mean to show love for the Vixen'? 


\section{Acknowledgements}

I am grateful to Paul Byron for the Facebook conversation that inspired this article, and to Tom Brassington for reminding me about the bus stop incident.

\section{References}

Ahmed, S., 2004. Affective Economies. Social Text, 22(2), pp. 117-139.

Aitkenhead, D. 2018. 'RuPaul: 'Drag is a big f-you to male-dominated culture', The Guardian, 3 March. Available at: https://tinyurl.com/y22urx66

Betancourt, M. 2016. 'RuPaul's Drag Race and the Art of Self-Love', The Atlantic, 14 May. Available at: https://tinyurl.com/y372asz5

Biressi, A. and Nunn, H. 2005. Reality TV: Realism and Revelation. London: Wallflower Press.

Blackman, L., and Walkerdine, V. 2001. Mass Hysteria: Critical Psychology and Media

Studies. London: Palgrave

Butler, J. 2014. 'Rethinking Vulnerability and Resistance' J. Butler, Z. Gambetti \& L. Sabsay, eds., Vulnerability in resistance,12-27. Durham, NC: Duke University Press.

Chatterjee, D. 2017. 'Mental Health is Different for People of Color in These 3 Ways', Mad in America, May 17. Available at: https://tinyurl.com/yykxrfbv

Cole, E. and Zucker, A. 2007. 'Black and White Women's Perspectives on Femininity', Cultural Diversity and Ethnic Minority Psychology 13 (1), 1 - 9.

Costa, L., Voronka, J., Landry, D., Reid, J., McFarlane, B. and Reville, D. 2012. 'Recovering our Stories: a small act of resistance', Studies in Social Justice 6 (1), 85 - 101.

Costa, L. (2014) 'Mad Studies - what it is and why you should care'. Mad Studies (blog). Available at: https://tinyurl.com/y59cos65.

Cross, S. 2004. Visualizing Madness: Mental Illness and Public Representation. Television and New Media 5 (3), 197-216.

Damshenas, S. 2018. 'Asia O'Hara "threatened to be burned alive" by racist Drag Race fans', Gay Times, 20 June. Available at: https://tinyurl.com/y3x67dcw 
Dry, J. 2018. 'RuPaul's Outburst on the 'Drag Race' Reunion Is the Most Powerful Moment of Season 10', Indiewire, June 21. Available at: https://tinyurl.com/y5x2jpk2

Ferreday, D. 2017. 'Like a Stone in Your Stomach: Articulating the Unspeakable in Rape VictimSurvivors' Activist Selfies' in Kuntsman, A., ed., Selfie Citizenship, London: Palgrave MacMillan, $127-136$.

Flores, B. 2017.'We Still Need to Talk About How Drag Race Treated Nina Bo'Nina Brown', Pride, June 29. Available at: https://tinyurl.com/y629a86x

Fossum, M. 2014. 'Sharon Needles on RuPaul's Drag Race: "They Took Away Our Booze and Terrorized Us"' New Times, May 20. Available at: https://tinyurl.com/y3vy6caa

Garvin, K. 2019. 'Sorry — Love You': Asian Americans on 'RuPaul's Drag Race', Clyde Fitch Report, March 23. Available at: http://tinyurl.com/yywxxrwl

Gilman, S. 1976. The Face of Madness: Hugh Diamond and the Origins of Psychiatric Photography. New York: Palatine

Griffin, R.A. 2012. 'I AM an Angry Black Woman: black feminist autoethnography, voice, and resistance'. Women's Studies in Communication 35 (2), 138 - 157.

Han, C. Winter 2015. Geisha of a different kind: race and sexuality in gaysian America. New York and London: New York University Press.

Hawbacker, K.T. and Tucker, S. 2016. 'Chicago's black drag queens are upholding a radical genderbending tradition, Chicago Tribune, August 11. Available at: https://tinyurl.com/ybhqm3w8

Illouz, E. (2003) Oprah Winfrey and the Glamour of Misery, New York: Colombia University Press.

LeFrancois, B., Menzies, R. and Reaume, G., eds. (2013) Mad Matters: a critical reader in Canadian mad studies. Toronto: Canadian Scholars' Press.

Love, H. 2007. Feeling Backward. Cambridge, MA: Harvard University Press.

Luckhurst, R. 2008. The Trauma Question. London: Routledge.

McDermott, E. and Roen, K. (2016) Queer Youth, Suicide and Self-Harm: Troubled Subjects, Troubling Norms. London: Palgrave MacMillan.

McFarland, M. 2016. 'RuPaul Gave Me Life: how Drag Race pulled me back from the depths of depression'. Salon, 22 March. Available at: https://tinyurl.com/y436pfso

McWade, B. 2018. 'Madness, Violence and Media' in Beresford, P., Daley, A. and Costa, L., eds., Madness, Violence and Power: a critical collection. Toronto: University of Toronto Press. 
Nichols, J.M. 2018. 'RuPaul's Drag Race Stars Open Up About Mental Health And The Toll Of

Superstardom', Huffington Post, 18 January. Available at: https://tinyurl.com/y3w5yobt

Ouellette, L. and Hay, J. 2008. Better Living Through Reality TV: Television and Post-Welfare

Citizenship. Malden, MA: Blackwell.

Puar, J. 2012. 'The Cost of Getting Better: Suicide, Sensation, Switchpoints'. A Journal of Lesbian and Gay Studies 18 (1), 149 - 158.

Rodriguez, M. 2018. 'How 'RuPaul's Drag Race' Makes Room for Queer Black Trauma', Into, 10 May. Available at: http://tinyurl.com/y6g468nz

Scudera, D. 2016. 'It Gets Better: drag edition', Huffpost, 2 February. Available at:

https://tinyurl.com/y36zmgau

Showalter, E. 1987. The Female Malady: Women, Madness and English Culture, 1830-1980. London: Virago 